\title{
NOUVELLE
}

\section{Des peptides cationiques antibactériens comme vecteurs de transfert de gènes}

\author{
Antoine Kichler, Burkhard Bechinger, Olivier Danos
}

> L'idée de base de la thérapie génique, qui est de transférer des acides nucléiques dans des cellules dans un but thérapeutique, s'applique aussi bien à la conception de traitements nouveaux pour des maladies génétiques ou acquises qu'à des approches innovantes de vaccination. Cependant, le prérequis pour une thérapie génique est de disposer d'un transporteur (ou vecteur) capable de transférer de manière efficace le gène thérapeutique dans les cellules cibles. Au cours de la dernière décennie, de nombreux vecteurs, biologiques et synthétiques, ont été développés. Malgré une efficacité plus faible que celle des meilleurs vecteurs viraux, les vecteurs non viraux sont attractifs pour plusieurs raisons, par exemple l'absence de contraintes liées à la taille du gène à transporter, ainsi que la sécurité, la versatilité et la facilité d'une production industrielle.

Bien que la synthèse de plusieurs centaines de composés ait permis d'identifier de bons outils pour la recherche fondamentale, l'efficacité de transfection de ces vecteurs non viraux est encore trop faible pour des applications à visées thérapeutiques. Le développement de nouvelles molécules reste donc nécessaire. Les vecteurs peptidiques sont parmi les moins explorés, bien qu'ils aient un potentiel élevé. La synthèse peptidique permet en effet d'obtenir des produits bien caractérisés et peut être effectuée à grande échelle. De plus, des peptides variants, voire résistants aux dégradations enzymatiques, sont facilement syn- thétisables. Jusqu'à récemment, les peptides ont été principalement utilisés comme agents auxiliaires pour d'autres systèmes de vectorisation, en particulier des polymères cationiques tels que la polylysine, auxquels ils peuvent apporter une fonction de ciblage cellulaire, une activité de type membranolytique ou encore un signal de localisation nucléaire [1]. Une stratégie émergente consiste à développer des peptides multifonctionnels, capables de délivrer sans adjuvant de I'ADN dans des cellules. Ainsi, notre groupe a montré que le fragment carboxy-terminal de la petite protéine Viral protein $R$ (Vpr) du VIH-l possède une activité de transfection comparable à celle d'agents cationiques lipidiques et polymériques [2].

Un agent transfectant doit remplir un cahier des charges minimal. Tout d'abord, le composé doit pouvoir interagir avec I'ADN de manière à favoriser son entrée dans les cellules. Si, comme c'est le cas pour la grande majorité des vecteurs synthétiques, l'entrée se fait par endocytose, le composé doit pouvoir déstabiliser la membrane endosomale avant que I'ADN ne soit dégradé dans le lysosome. Une fois relargué dans le cytosol, I'ADN peut pénétrer dans le noyau au cours de la division cellulaire, lorsque l'enveloppe nucléaire est disloquée. En tenant compte de ces propriétés minimales requises, nous avons défini les caractéristiques suivantes comme étant essentielles pour nos peptides: (1) une séquence relativement courte (<30 acides aminés); (2) une
A. Kichler, 0. Danos:

Genethon-Cnrs UMR 8115,

1 , rue de l'Internationale,

91000 Évry, France.

B. Bechinger: Faculté de

chimie, FRE 2446,

4 , rue Blaise Pascal,

67000 Strasbourg, France. akich@genethon.fr

densité de charges positives suffisante pour former un complexe avec l'ADN (qui est une macromolécule polyanionique), mais pas trop forte afin de réduire les possibilités d'activation du système $d u$ complément; (3) une séquence conférant des propriétés amphipathiques et perméabilisantes; (4) la présence de résidus histidines qui ont la capacité d'améliorer le relargage de I'ADN des endosomes dans le cytosol via un mécanisme similaire à celui des polyéthylènimines [3]. Or, certains peptides antimicrobiens naturellement présents dans le règne animal, y compris chez l'homme, répondent à ces critères [4]. Pour évaluer leur intérêt en tant que vecteurs de transfert de gènes, nous avons utilisé des peptides antibiotiques modèles, dont un des représentants est LAH4 [5]. Outre la présence à chaque extrémité de 2 lysines qui apportent les charges positives, ce peptide est à la fois amphipathique et capable de déstabiliser des membranes. En utilisant des mutants de LAH4 comportant entre 1 et 5 histidines, nous avons pu montrer que la capacité de transfection est maximale lorsqu'au moins 4 histidines sont présentes [6]. Les activités obtenues sur différentes lignées cellulaires indiquent que l'efficacité de LAH4 est comparable à celle d'agents transfectants commercialisés comme le lipide cationique DOTAP. Un dérivé dans lequel les 4 histidines de LAH4 ont été remplacées par des lysines est environ 1000 fois moins actif que LAH4 pour ce qui est de l'efficacité de transfection, alors qu'il condense bien 
I'ADN. Cela démontre que la compaction de I'ADN ne suffit pas pour obtenir une transfection efficace, et que les résidus histidines jouent un rôle clé lors du transfert de gènes. Grâce à la synthèse de différents peptides mutants, nous avons pu mettre en évidence d'autres paramètres cruciaux pour le maintien de l'activité du peptide: (1) le peptide doit pouvoir adopter une conformation $\alpha$-hélicoïdale; (2) outre leur nombre, la position des histidines dans la séquence est importante; (3) le $\mathrm{pH}$ auquel le peptide passe d'une orientation transmembranaire à un alignement parallèle à la membrane doit être proche de 6 (Figure I).

Même associé à l'ADN, LAH4 conserve son activité antibiotique [6]. On peut imaginer que cela soit utile dans le contexte d'un transfert de gène thérapeutique chez les patients, en particulier chez ceux qui, atteints de mucovis- cidose, développent des infections bactériennes récurrentes associées à une altération progressive et irréversible des poumons [7].

Les peptides antimicrobiens sont considérés comme les composants clés des systèmes de défense immunitaire innée (qui constituent la première ligne de défense contre les infections). Plusieurs centaines de peptides ont été caractérisés à ce jour [8], révélant une grande diversité structurale et un large spectre d'activité. La conception de nouveaux vecteurs de transfert de gènes tirera sans doute un grand profit de la formidable variété de peptides cationiques naturels. $\diamond$

Antimicrobial peptides

\section{as efficient DNA vectors}

\section{REMERCIEMENTS}

Ce travail a été effectué avec le soutien du Cnrs, de l'AFM et de Vaincre la mucoviscidose.

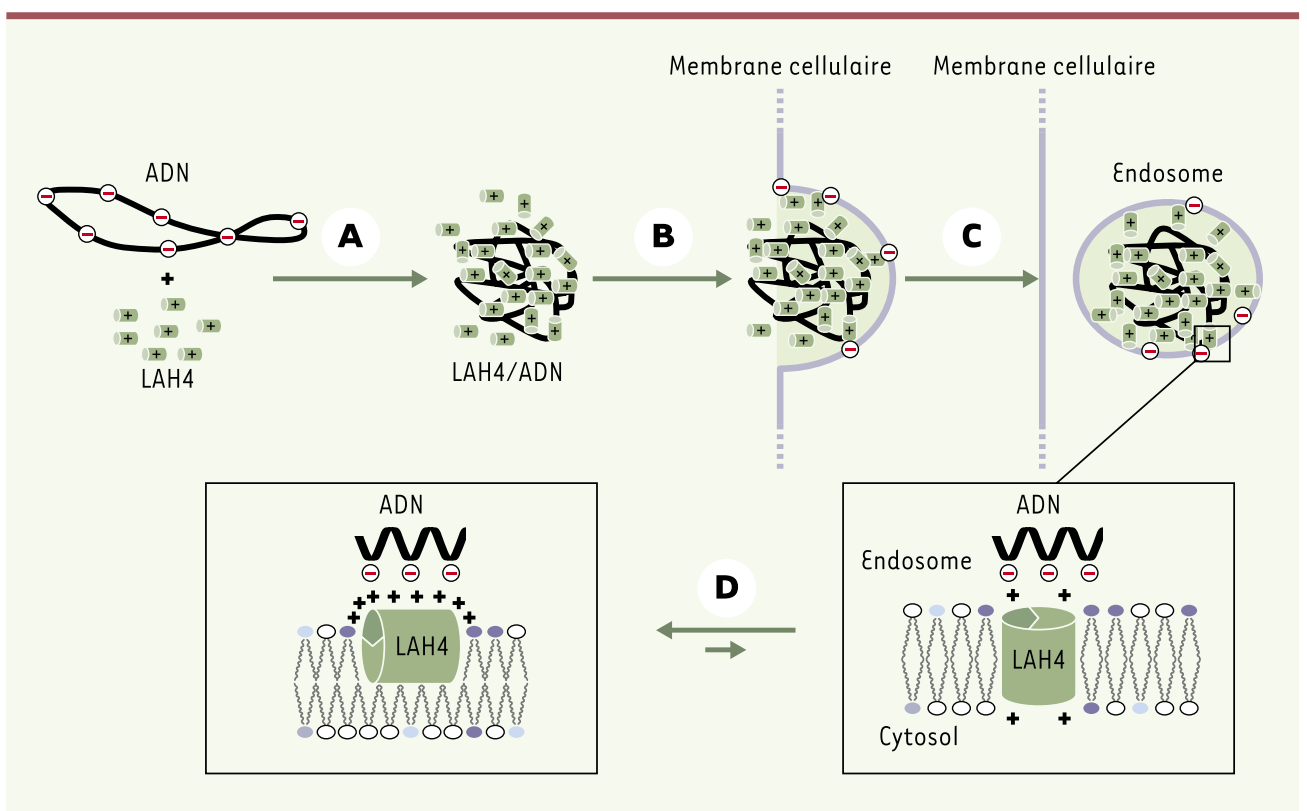

Figure 1. Modélisation des premières étapes de transfection. A. Formation des complexes LAH4/ADN. B. Les particules interagissent par l'intermédiaire de liaisons ioniques avec les charges négatives des protéoglycanes présents à la surface cellulaire. C. Les complexes pénètrent par endocytose. LAH4 adopte majoritairement une orientation transmembranaire. D. L'acidification des endosomes entraîne la protonation des résidus histidines du peptide. Celui-ci s'oriente alors parallèlement à la surface membranaire, la partie hydrophobe pénétrant profondément dans la bicouche. Lorsqu'une concentration critique de peptide est atteinte, la membrane est perméabilisée par un mécanisme sans doute proche de celui de détergents, permettant ainsi le passage de l'ADN dans le cytosol.

\section{RÉFÉRENCES}

1. Mahato RI, Monera OD, Smith LC, Rolland A. Peptide-based gene delivery. Curr Opin Mol Ther 1999; 1: 226-43.

2. Kichler A, Pages JC, Leborgne $C$, et al. Efficient DNA transfection mediated by the $\mathrm{C}$-terminal domain of human immunodeficiency virus type 1 viral protein R. J Virol 2000; 74 : 5424-31.

3. Midoux P, Monsigny M. Efficient gene transfer by histidylated polylysine/pDNA complexes. Bioconjug Chem 1999; 10: 406-11.

4. Tossi A, Sandri L, Giangaspero A. Amphipathic, alpha-helical antimicrobial peptides. Biopolymers 2000; 55: 4-30.

5. Vogt TC, Bechinger B. The interactions of histidinecontaining amphipathic helical peptide antibiotics with lipid bilayers. The effects of charges and $\mathrm{pH}$. J Biol Chem 1999; 274 : 29115-21.

6. Kichler A, Leborgne C, Marz J, Danos 0, Bechinger B. Histidine-rich amphipathic peptide antibiotics promote efficient delivery of DNA into mammalian cells. Proc Natl Acad Sci USA 2003; 100: 1564-8.

7. Travis SM, Singh PK, Welsh MJ. Antimicrobial peptides and proteins in the innate defense of the airway surface. Curr Opin Immunol 2001; 13: 89-95.

8. www.bbcm.univ.trieste.it/ tossi/pagl.htm 